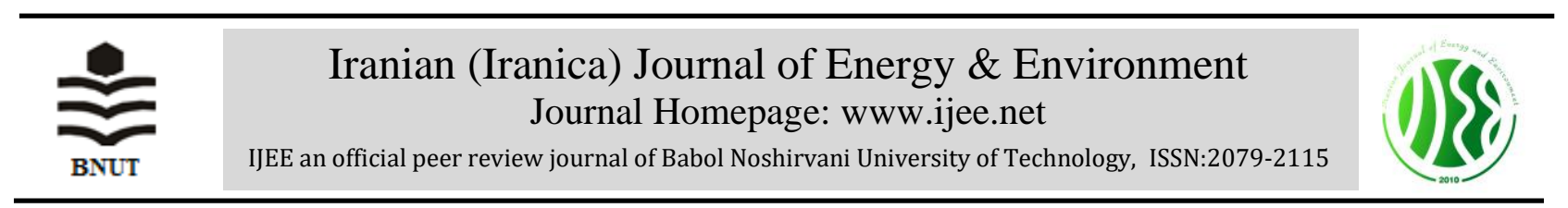

Technical Note

\title{
Customer and Model Based Performance Evaluation of Water Distribution Systems: The case of Adama Town, Ethiopia
}

\author{
W. M. Desta*, A. Befkadu \\ Department of Water Supply and Environmental Engineering, Faculty of Civil and Environmental Engineering, Jimma Institute of Technology, \\ Jimma University, Jimma, Ethiopia
}

\section{$P A P E R \quad I N F O$}

\section{Paper history:}

Received 27 November 2019

Accepted in revised form 23 February 2020

\section{Keywords:}

Performance Evaluation

Water Distribution Networks

Waternetgen Tools

Water Tap Flow Analysis

\begin{abstract}
$\begin{array}{llllllllllllllll}A & B & S & T & R & A & C & T\end{array}$
The aim of this study was to evaluate the performance of the existing water supply system of Adama Town by considering direct and indirect performance measurements. The paper also investigates the application of technical performance index to evaluate the operational performance of the water distribution system and to easily identify the critical areas in the network. The evaluation carried out based on WaterNetGen tools an extension of EPANET to attain direct performance measurement and Minitab16 software to analyze primary data to achieved indirect performance measurement. Based on water tap flows result, most of the residences got water at night time and were not satisfied with the town water supply services. The greatest minimum slack pressure and velocity occurred in a small area of the network, and the global technical performance index of pressure and velocity were $35.75 \%$ and $46.19 \%$, respectively.
\end{abstract}

doi: 10.5829/ijee.2020.11.01.03

\section{INTRODUCTION}

Water is the most abundant natural resource and is a prime necessity for all living beings [1, 2]. However, the need for potable water is not still satisfied and the potential is not yet expected.

One of the most important performance indicators in water supply distribution network is availability of optimum pressure at networks head and flow velocity in pipes. However, problems in providing satisfactory water supply to the rapidly growing urban population especially that of the developing countries is increasing from time to time. Adama is one of the towns in Ethiopia and have such kinds of water distribution problem. All water supply network pipe line was installed before most of the existing road access and residential building is constructed just only using the oldest master plan.

Water distribution system is one of the most important infrastructures in city or town and it's closely related to people's society life [3]; it includes many elements such as: pipes; valves; pumps; tanks; reservoirs; flow regulating and control device [4]. But, due to fluctuating, programmed operations, anticipated hazards, aging, deterioration, redesign and expansion [5] water supply and distribution is a complex system. In addition to its complexity, the system faces multiple internal and external development pressures during their lifespan. Systems have to be continuously adapted in order to guarantee a sufficient high level of service at all times [6]. So, the future development of water consumption is highly unsure; it depends on multiple factors, such as changes in population and consumption patterns, climate change, variations of land use, tourism and economic trends. Therefore, there is a need for regular review on water distribution system because of the varying demands with time. Such as, a computer model can predict pressures, velocity and flows within a water system to evaluate a design and compare system performance against design standards [7]. WaterNetGen is one of computer modeling software which is being used for the whole work; it is useful in designing, optimizing and evaluating the water distribution network [8]. This software package also evaluates the performance value of each node and links.

According to literature [9], performance evaluation can be defined as 'any approach that allows for the evaluation of the efficiency or the effectiveness of a process or activity through the production of performance measurements. Performance measurements are distribution system characteristics that can be objectively quantified. These characteristics include the distribution system attributes with which water utility personnel are most familiar. Performance can be measured directly and indirectly, an example of direct performance measure is measuring of pressure using pressure gauges and

*Corresponding Author Email: wendemekonin27@gmail.com(W. M. Desta) 
software package and of indirect performance measurement is information obtain from customer and water utility [1]. Therefore, the objective of the present study was to evaluate the performance of the exciting water distribution system so as to identify the problematic zones and also to compare the two performance measurements based on obtained results.

\section{MATERIALS AND METHODS}

\section{Description of the study area}

One way of describing location is utilizing both direction and latitude - longitude points. Accordingly, Adama is located within grid references point that stretches between $8^{0} 23^{\prime} 30^{\prime \prime}$ to $8^{0} 25^{\prime} 30^{\prime \prime}$ North latitude and $39^{\circ} 19^{\prime} 0^{\prime \prime}$ to $39^{\circ} 20^{\prime} 30^{\prime \prime}$ East longitude, and $100 \mathrm{~km}$ far away from Addis Ababa Capital City of Ethiopia (Figure 1). Adama is characterized by very flat and plain of low land rounded by a lot of mountains. Thus, because of its topographic features area of the town is deeply deselected by numerous valleys formed by the seasonal rivers crossing the town. These streams are irregular in nature. As regard to the proposed expansion, most of the areas are characterized by flat and undulated plains as well as mountain natural barrier.

\section{Evaluation tools}

The evaluation tools used for the present study was WaterNetGen which is an EPANET extension for automatically build water distribution network synthetic models; do pipe sizing, compute technical performance indicators, and allowed demand-driven and pressure-driven simulations [10]. In addition to such applicability, it also allows evaluating technical performance and the analysis of critical scenarios, like firefighting or pipe bursts; and, it was now adapted to also solve an optimal operation model [11].

\section{Study design}

The research strategy chosen for this study was cross sectional study so as to determine the efficiency and effectiveness of the hydraulic performance in the distribution system (Figure 2).

\section{Sample size determination for indirect performance evaluation}

Since a complete listing of household in the survey area was not available, clustered sampling used for this study.
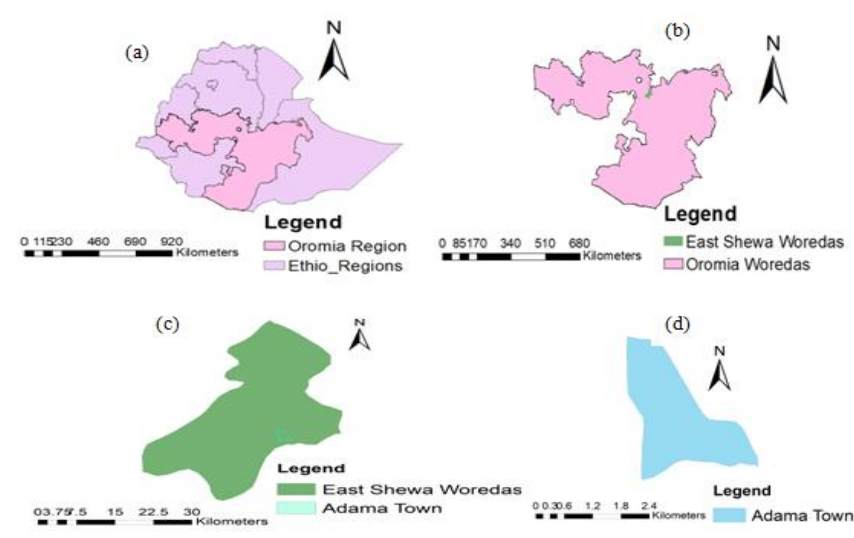

Figure 1. Map of study area

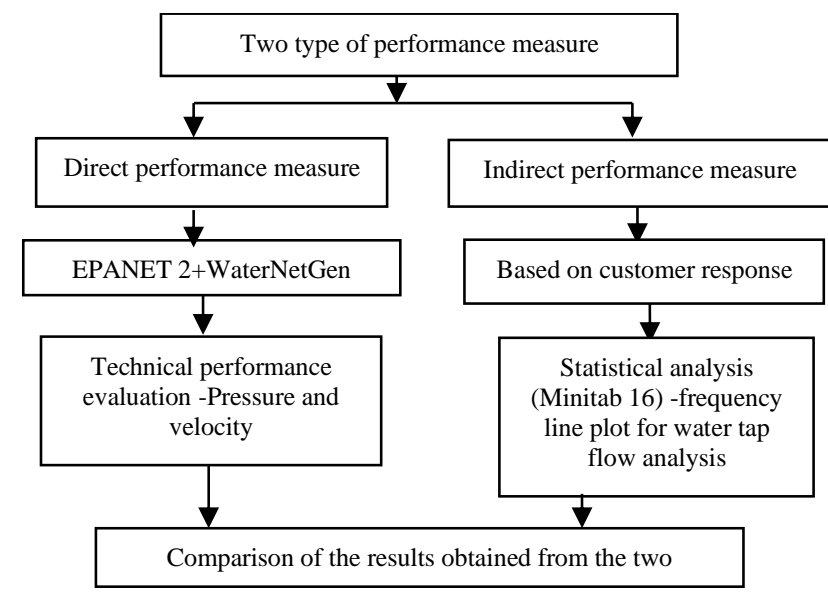

Figure 2. Flow of study design

Clustering of Kebele (smallest administrative unit) was based on population size, the old and new establishment area of the town and availability of data. Based on this classification, nine Kebele were selected out of eighteen Kebele as the study site. Accordingly, 100 household heads that were randomly included in one cluster so, totally 900 respondents were participated.

\section{Technical performance analyses}

The global technical performance indexes are computed by applying the generalization operator. This evaluation of TPIs was done by WaterNetGen software. And then by selecting the constraint (velocity and pressure) again the model was simulated and collected the performance value of pressure and velocity from each nodes and links. So that, according to literature [9], the global performance index for pressure and velocity computed by using the following formula:

$$
\begin{aligned}
& T P I_{\text {press }}=\sum_{i=1}^{N N} w_{i} p_{i} \\
& w_{i}=\frac{Q_{i}}{\sum_{j}^{N N} Q_{j}} \\
& T P I_{\text {vel }}=\sum_{k=1}^{N P} w_{k} p_{k} \\
& w_{k}=\frac{L_{k} D^{2}{ }_{k}}{\sum_{j}^{N P} L_{j} D^{2}{ }_{j}}
\end{aligned}
$$

Based on literature [9], definition :- NN: is the number of node in the network; $\mathrm{p}_{\mathrm{i}}$ : is the performance value; $\mathrm{w}_{\mathrm{i}}$ : is the weight; $\mathrm{Q}_{\mathrm{i}}$ : is the water demand of node $\mathrm{i} ; \mathrm{Q}_{\mathrm{j}}$ : water demand at all node; NP: is the number of pipes in the network; $p_{k}$ : is the performance value; $\mathrm{w}_{\mathrm{k}}$ : is the weight; $\mathrm{L}_{\mathrm{k}}$ and $\mathrm{D}_{\mathrm{k}}$ are the length and diameter of pipe $\mathrm{k}$; $\mathrm{TPI}_{\text {press: }}$ technical performance index for nodal pressure state variable and; $\mathrm{TPI}_{\mathrm{vel}}$ : technical performance index for pipe flow velocity state variable. As depicted in Figure 3, the performance curve developed in WaterNetGen windows based on adjusted equation on the software indicated that, performance value between $0 \%$ (no service) and $100 \%$ (optimum service). This means that, no service level occurred at $75 \%$ of minimum pressure and $50 \%$ of maximum velocity in the distribution system; while optimum service level occurred when the pressure and velocity in the distribution system meted the minimum and maximum design criteria, respectively. 

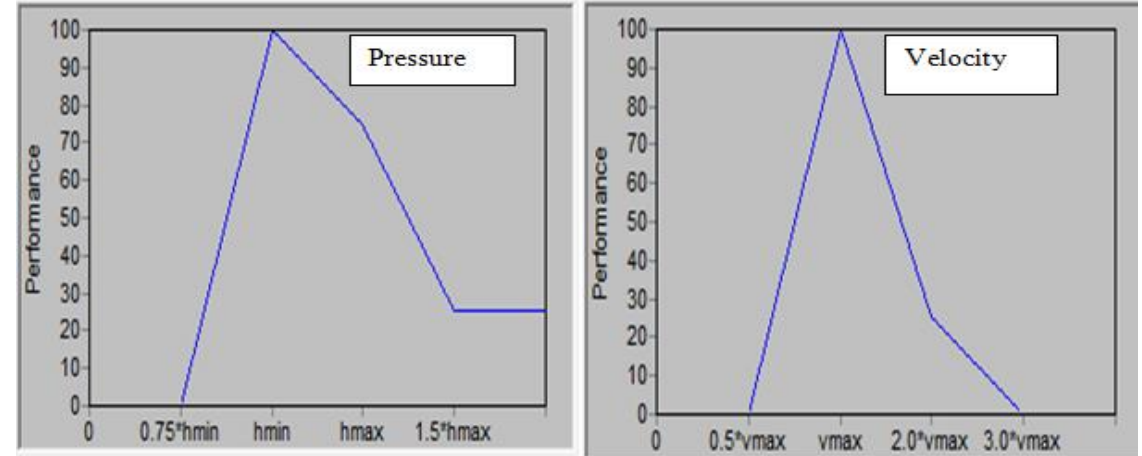

Figure 3. Nodal pressure and pipe flow velocity performance curves

\section{RESULTS AND DISCUSSION}

The performance analyses were conducted by WaterNetGen software (direct) and customer response (indirect). The case in point network encompasses 137 junctions, 174 pipes, 3 reservoirs and 1 pump. The network supposed to supply 301,617 inhabitants which correspond to an average demand of $39.93 \mathrm{l} / \mathrm{s}$ with a demand pattern shown in the Figure 4 . As Figure 4 shows that, maximum multiplier was from 18 to 21 hours whereas; the minimum one was from 3 to 6 hours. This indicated that, the maximum flow of water occurred at low demand period (night time). The $\mathrm{x}$-axis indicates time period, where as the $y$-axis indicates the multiplier.

\section{Water tap flow of the town}

As indicated in Figure 2, customer responses were one of indirect measure of the performance of water distribution system. The questions were prepared based on the basis of maximum and minimum water demand and analyzed in detail using Minitab 16.

Figure 5 depicted that; the tap received maximum water at the morning time which indicated by black color only in Kebele 10,11, 13 and Boku Shanan. This indicated that, during maximum demand period the tap flows at high rate and satisfies the demand. This was because of those Kebele were situated near to the source. Whereas other Kebele got minimum water during peak hour period (morning time); this

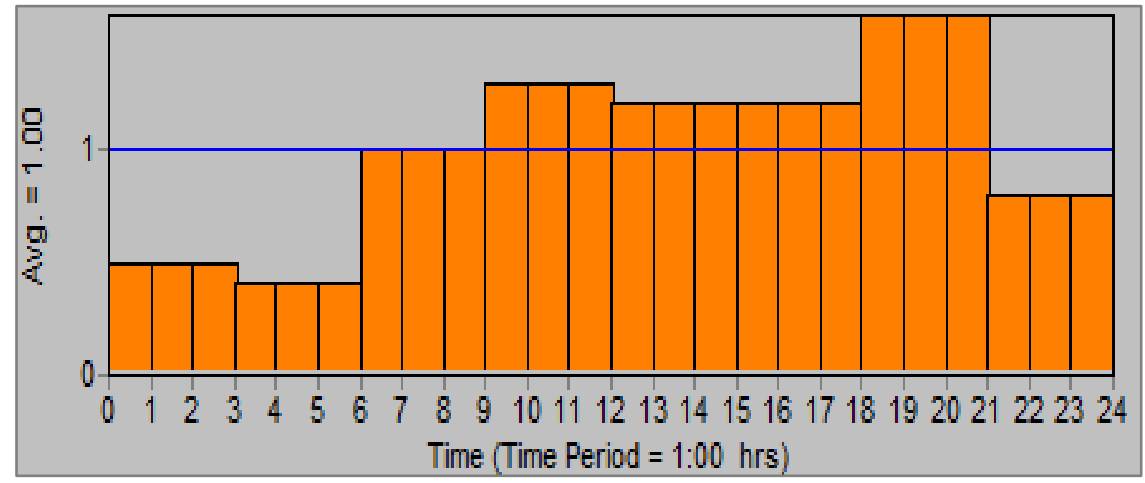

Figure 4. Demand pattern

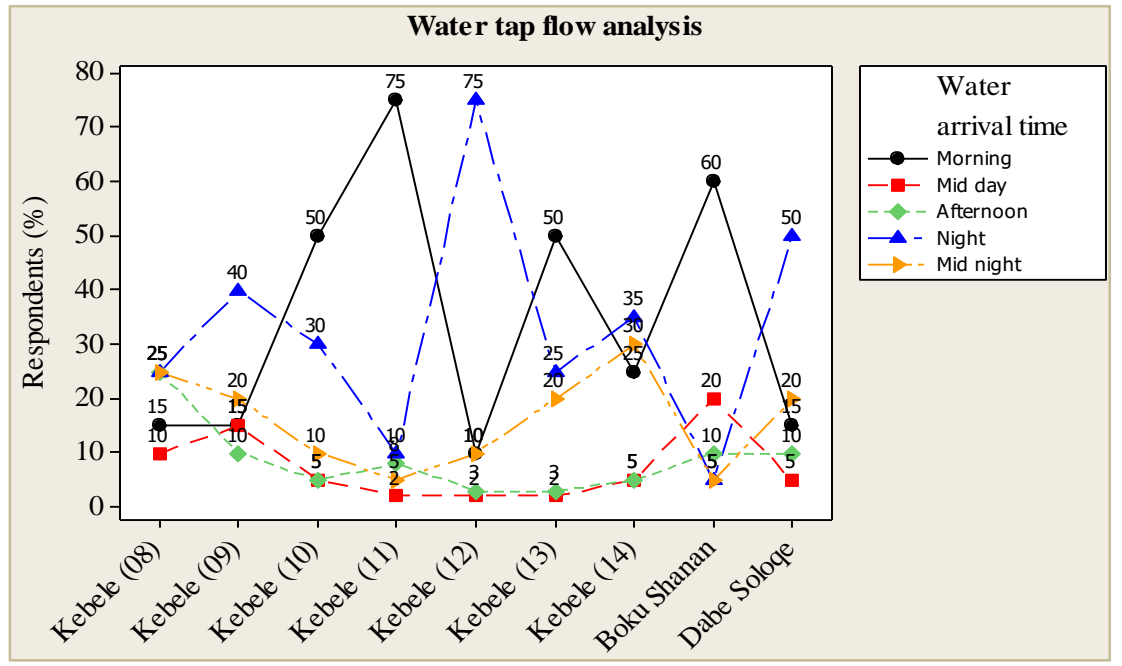

Figure 5. Water tap flow analysis results 
was because of the area especially Kebele 09 was far from the source and received low pressure. This indicated that, the pressure was high at low demand period and low at peak hour (morning) time. So, the consumer did not have sufficient amount of water during high demand period. Generally, this analyzed result shows that; the flow of water in each selected Kebele with referenced time zones.

Technical performance evaluation of pressure and velocity in the network

The maximum demand occurs at the morning and evening time, the reason that, Figure 6 simulations was done at this time. But, the result obtained from this type of analysis did not indicate the performance of the network. Because high pressure value may have good or bad performance and also low pressure value may have good or bad performance (Figures 6 and 7).

\section{Technical performance of pressure}

The node was highlighted by different colors but, it was difficult to say red node have good or bad performance
(Figure 6). The model simulated in Figure 7 can solve such difficulty. In this regard, the pressure at peak hour period was enough to maintain the minimum design criteria so as to reduce the above problem. With this remark Figure 7 was developed by considering peak hour period.

As can be seen from Figure 7, most of the areas had low performance in maintaining minimum pressure at peak hour period. Only small parts of the area maintain the performance of pressure in range $60-80 \%$. The global performance index of the networks was computed using Equations (1) and (2). So, the global performance index of pressure at the greatest consumption was $35.75 \%$, this indicated the performance of the distribution system was low. But, the performance value $35.75 \%$ from Figure 3 may due to insufficient energy (current pressure below minimum required pressure) or surplus energy (current pressure above maximum required pressure). Again this problem was solved by using slack variable concept.

The slack network shows the slack of each element. Based on Figure 8, the greatest slack occurred at only small part of the area; the reason that, those areas were situated near to the main source of the distribution system. This indicated that, these areas were the most preferable point for future network expansion.

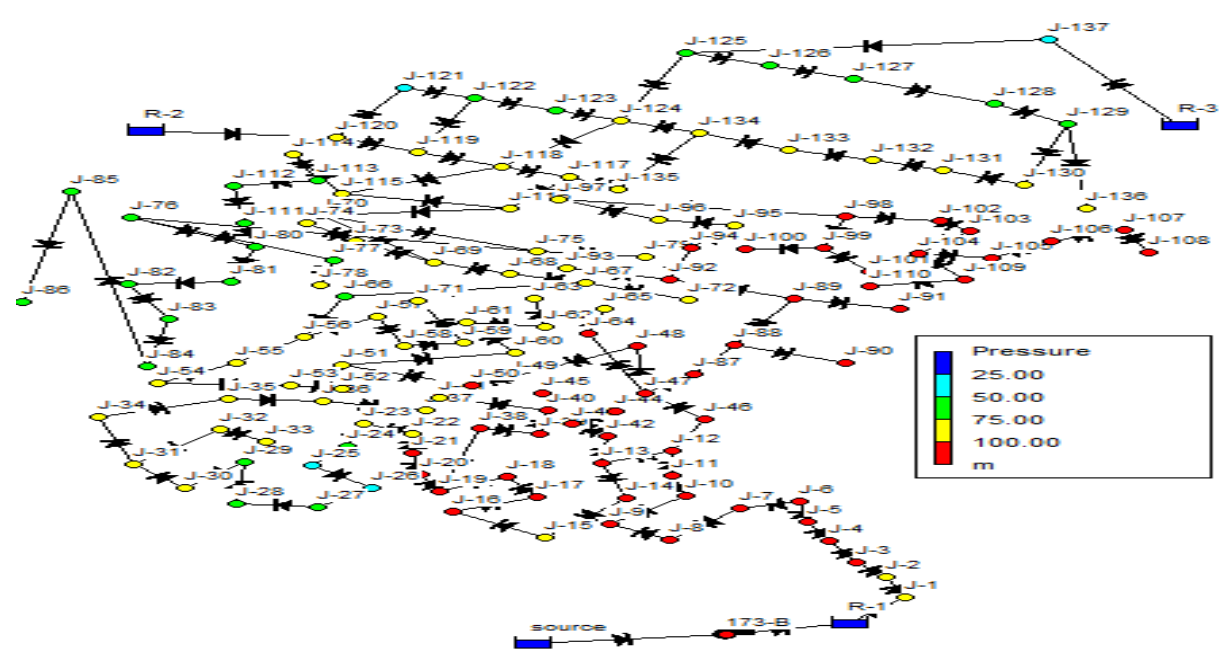

Figure 6. Simulated pressure at peak hour demand

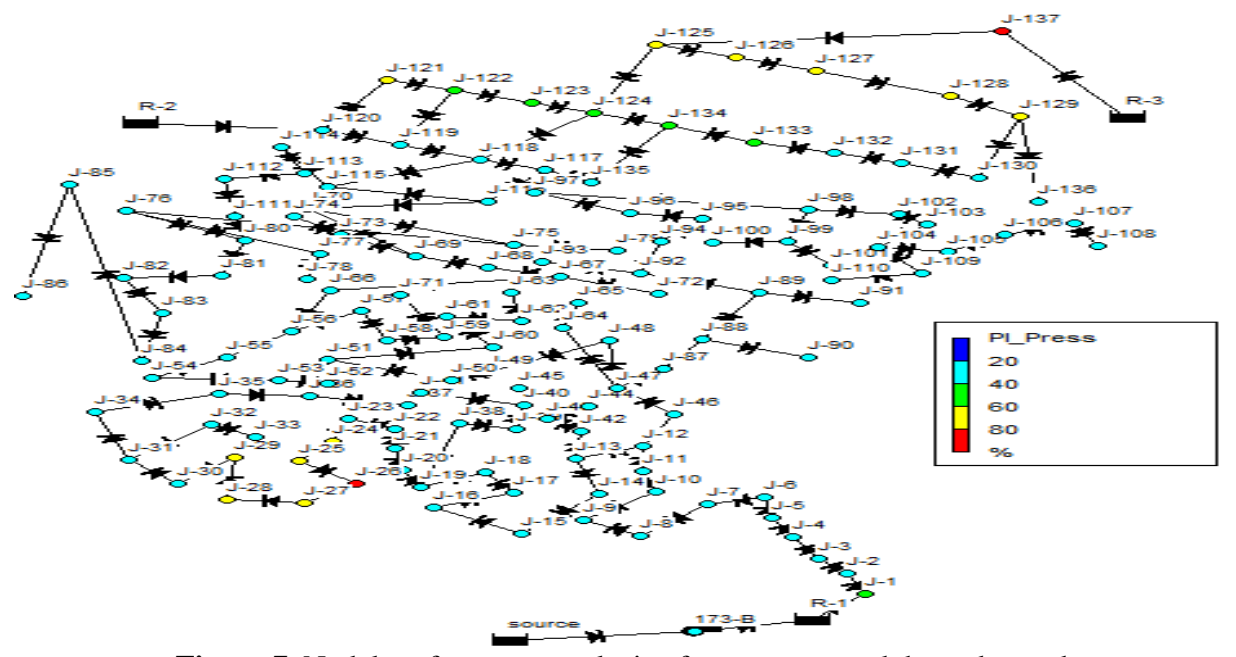

Figure 7. Nodal performance analysis of pressure at peak hour demand 


\section{Technical performance of velocity}

As Figure 9 shows that, in most of the area the velocity at maximum consumption was failed to maintain the maximum require that satisfied the need. However, the velocity in area which situated near to the source meted the need.

The global performance index of the networks was computed using Equations. (3) and (4). So, that the global performance index of velocity at the greatest consumption was $46.19 \%$.
In similar concept in the evaluation of the performance of pressure, this value may be due to excess or lower velocity in the network. According to literature [9], WaterNetGen tool can be used to surpass this problem as shown in figure 10 using slack variable concept.

As shown in the Figure 10, greater minimum velocity slack was occurred in a small area of the network. But, most of the areas have low minimum velocity slack. This indicated that, the velocity in those areas did not meet the maximum

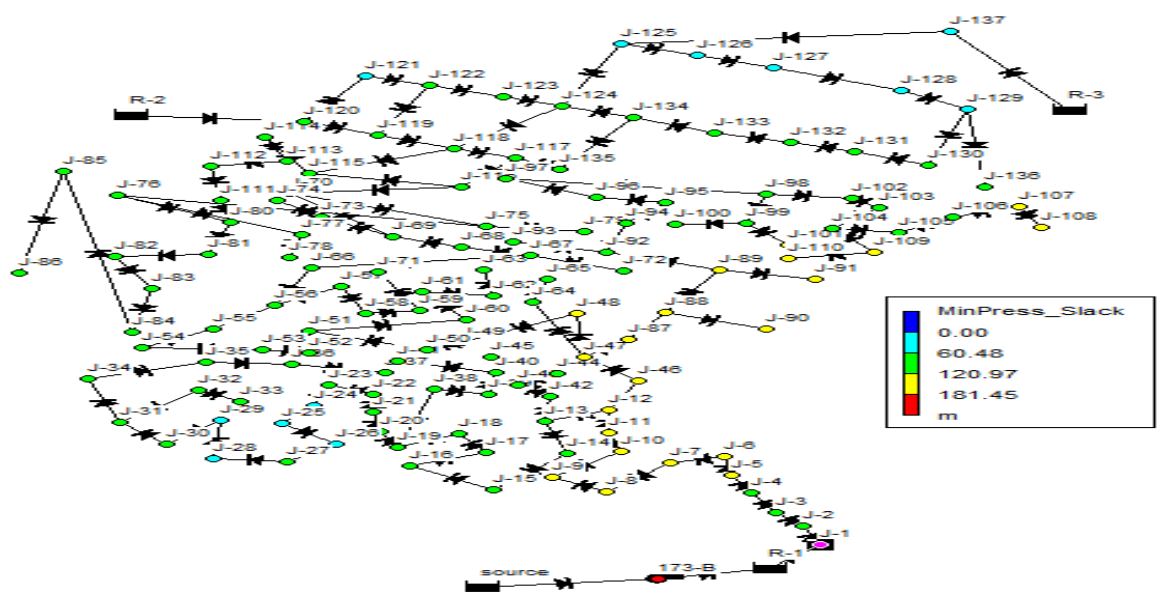

Figure 8. Minimum pressure network slack

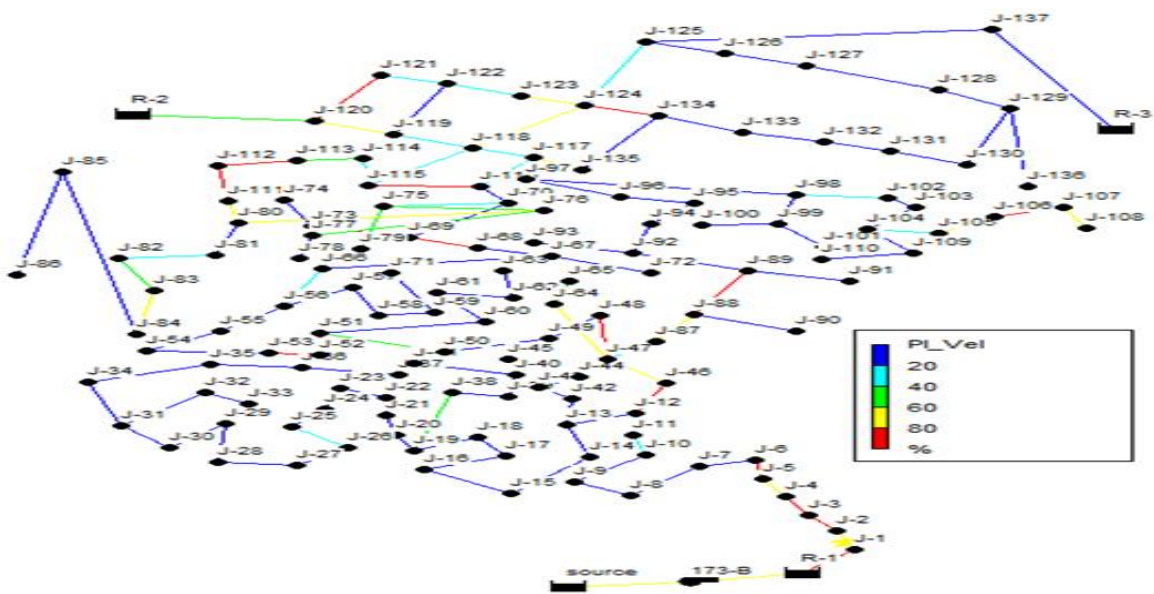

Figure 9. Link performance analysis of velocity at high consumption

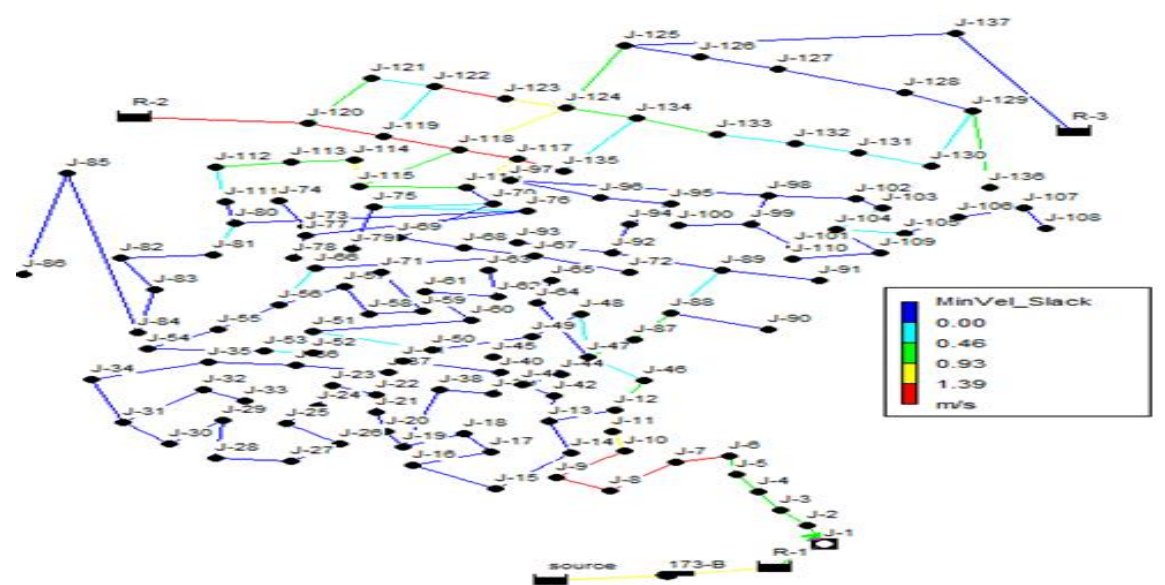

Figure 10. Minimum velocity slack networks 
required during high consumption period. Generally, the velocity in most of the distribution system was low, and provided in sufficient water at the customer tap.

\section{Direct and indirect methods comparison}

As depicted in Table 1, 124 out of 137 nodes and 109 out of 147 pipes have a performance value of less than or equal to $50 \%$. Similarly, 7 out of 9 kebele got insufficient water during this time based on customer reviewed result. Therefore, both methods proved that, the distribution system in the town was in poor situation.

TABLE 1. Comparison of customer response and obtained model value at morning time

\begin{tabular}{lcccc}
\hline & \multicolumn{4}{c}{ Pi, pk and respondent, all in \% age } \\
\cline { 2 - 5 } Item & $\mathbf{( 0 - 2 5 )}$ & $\mathbf{( 2 5 - 5 0 )}$ & $\mathbf{( 5 0 - 7 5 )}$ & $\mathbf{( 7 5 - 1 0 0 )}$ \\
\hline No. of node count & 0 & 124 & 4 & 9 \\
No. of pipe count & 95 & 14 & 10 & 28 \\
No. of kebele count & 5 & 2 & 2 & 0 \\
\hline Pi perfor
\end{tabular}

$\mathrm{Pi}=$ performance value of pressure at node

$\mathrm{Pk}=$ performance value of velocity in pipe

\section{CONCLUSION}

A recent application in computing software's plays a big role for design, simulation and for other various purposes of the water distribution network. The use of WaterNetGen has greater acceptance in terms of simplified model building, like hydraulic modeling. The implementation of technical performance index (TPIs) of water distribution systems could be suitable method to detect for critical zones, thus helping to decision makers to improve water supply service. Accordingly, the performance value of pressure and velocity in each node and pipe was evaluated; this performance value indicated the excess and deficiency of energy in each specific node. And also the minimum slack value of pressure and velocity for each area was evaluated. This slack value was importance to save energy lost in the distribution system and to determine future network expiation area.

In general, from hydraulic point of view modeling results showed that, Adama Town water supply system was currently performing in a poor situation. Particularly, the subsystem was not maintaining the minimum and maximum pressure. So, the existing water distribution system should be improved or upgraded by resizing the pipe, increasing the source and dividing the area into different pressure zone. It is important to use SCADA system in order to solve any water distribution system problems. This software has a wide application in any organization or industries.

\section{ACKNOWLEDGMENTS}

The authors would like to thanks Jimma University, Jimma Institute of Technology, Environmental Engineering chair for their supporting all times with work in partnership.

\section{REFERENCE}

1. Deb, A.K., Hasit, Y.J. and Grablutz, F.M., 1995. Distribution system performance evaluation. American Water Works Association.

2. Dabgerwal, D.K. and Tripathi, S.K., 2016. Assessment of surface water quality using hierarchical cluster analysis. International Journal of Environment, 5(1), pp.32-44.

3. Li, S., Wang, R., Wu, W., Sun, J. and Jing, Y., 2015. Non-hydraulic factors analysis of pipe burst in water distribution systems. Procedia Engineering, 119, pp.53-62.

4. Bello, A.A.D., Alayande, W.A., Otun, J.A., Ismail, A. and Lawan, U.F., 2015. Optimization of the Designed Water Distribution System Using MATLAB. International Journal of Hydraulic Engineering, 4(2), pp.37-44.

5. Matos, J.P., Monteiro, A.J., Matias, N. and Schleiss, A.J., 2014. Guided evolutionary approaches for redesigning water distribution networks. Procedia Engineering, 89, pp.87-94.

6. Zischg, J., Mair, M., Rauch, W. and Sitzenfrei, R., 2017. Enabling efficient and sustainable transitions of water distribution systems under network structure uncertainty. Water, 9(715), pp.1-15.

7. AWWA, 2005. Computer modeling of water distribution systems (Vol. 32). American Water Works Association.

8. Nigam, U., Tiwari, K., Yadav, S.M., and Mehta, D., 2015. Water Distribution Network Re-Design for Svnit Surat Campus, International Journal of Advance Research in Engineering, Science \& Technology, 2(5), pp.1-9.

9. Muranho, J., Ferreira, A., Sousa, J., Gomes, A. and Marques, A.S., 2014. Technical performance evaluation of water distribution networks based on EPANET. Procedia Engineering, 70, pp.1201-1210.

10. Muranho, J., Ferreira, A., Sousa, J., Gomes, A. and Marques, A.S., 2012. WaterNetGen: an EPANET extension for automatic water distribution network models generation and pipe sizing. Water Science and Technology: Water Supply, 12(1), pp.117-123.

11. Sousa, J., Muranho, J., Sá Marques, A. and Gomes, R., 2014 WaterNetGen helps C-town. Procedia Engineering, 89, pp.103-110.

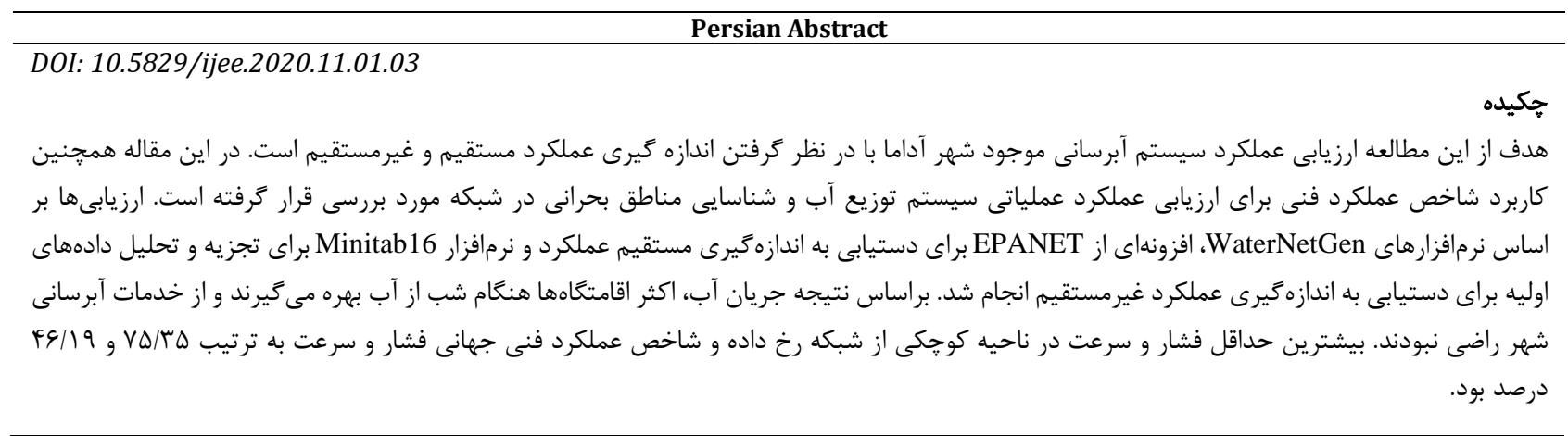

